\title{
Combination therapy of angiotensin receptor blocker with statin or thiazolidinediones as promising therapeutic strategy for metabolic syndrome and atherosclerosis
}

\author{
Shokei Kim-Mitsuyama \\ Hypertension Research (2009) 32, 639-640; doi:10.1038/hr.2009.90; published online 19 June 2009
}

$\mathrm{H}$ ypertension, insulin resistance/type 2 diabetes and hypercholesterolemia are closely associated with each other, and they all cause vascular endothelial dysfunction, develop atherosclerosis and consequently increase cardiovascular morbidity and mortality. ${ }^{1}$ Very importantly, there is a strong synergy among hypertension, type 2 diabetes, and hypercholesterolemia in terms of the risk factors for the development of cardiovascular diseases. The frequent association of these diseases aggravates the process of vascular endothelial dysfunction and atherosclerosis in patients with these comorbid conditions.

Renin-angiotensin system (RAS) blockers, such as angiotensin-converting enzyme inhibitors and AT1 receptor blockers (ARBs), are shown to be effective for the treatment of not only hypertension but also cardiovascular and renal diseases, by exerting multiple pleiotropic effects, including the suppression of cardiovascular hypertrophy and remodeling, the improvement of insulin sensitivity and vascular endothelial function, and antiinflammatory and antioxidative effects. ${ }^{2-4}$ Furthermore, RAS blockers are reported to reduce the incidence of new-onset diabetes in high-risk or hypertensive patients. $^{5}$ 3-hydroxy-3-methylglutaryl coenzyme A (HMG CoA) reductase inhibitors (statins) are the most popular drugs for treatment of hypercholesterolemia and are shown to reduce cardiovascular morbidity and mortality in high-risk patients. ${ }^{1,6}$ Similar to RAS blockers, statins are well-known to

Professor S Kim-Mitsuyama is at the Department of Pharmacology and Molecular Therapeutics, Kumamoto University Graduate School of Medical Sciences, 1-1-1 Honjyo, Kumamoto 860-8556, Japan.

E-mail: kimmitsu@gpo.kumamoto-u.ac.jp have multiple protective effects against vascular endothelial dysfunction and atherosclerosis, being mediated by anti-inflammatory and antioxidative effects. ${ }^{1,7}$ Interestingly, in both preclinical and clinical studies, the combination of an RAS blocker and a statin is reported to provide additive beneficial effects on vascular endothelial dysfunction, atherosclerosis, inflammation or oxidative stress.

In this issue of Hypertension Research, Kanno et al., ${ }^{8}$ have extended the benefits of combination therapy of a statin and an ARB. They have shown that the combination of pravastatin and olmesartan provided a synergistic improvement of glucose tolerance in type 2 diabetic mice, and this synergistic effect was associated with the enhancement of glucose uptake in skeletal muscle and adipose tissue. They have also demonstrated that the attenuation of tissue oxidative stress by combination therapy is involved in the synergistic improvement of insulin sensitivity due to the combination. Furthermore, the same group of investigators has previously reported that a statin (fluvastatin) enhances the inhibitory effects of an ARB (valsartan) on atherosclerotic changes in apolipoprotein E-deficient mice. ${ }^{9}$ Taken together, Kanno et al., ${ }^{8}$ propose that the combination of a statin and an ARB could confer a promising therapeutic strategy for metabolic syndrome and atherosclerosis.

Previously, we have also reported that the combination of an ARB (olmesartan) and a statin (pravastatin) offers more beneficial effects on cardiovascular hypertrophy and remodeling, and vascular endothelial dysfunction in salt-loaded Dahl salt-sensitive hypertensive rats (DS rats) than does either monotherapy. ${ }^{10}$ Greater protective effects of their combination against cardiovascular remodeling in DS rats are at least partially attributed to a greater attenuation of tissue oxidative stress and inflammation, independent of blood pressure and plasma cholesterol control. Furthermore, the additive improvement of the vascular endothelial function by the combination is mediated by both the inhibition of endothelial nitric oxide synthase uncoupling by olmesartan and the enhancement of Akt phosphorylation by pravastatin. Our previous study ${ }^{10}$ provides the mechanisms underlying earlier clinical findings ${ }^{11}$ that the combination of a statin (simvastatin) with an ARB (losartan) improves endothelial function and reduces inflammatory markers to a greater extent than does either monotherapy in hypercholesterolemic, hypertensive patients. Taken together with the report by Kanno et al., ${ }^{8}$ the combination of a statin and an ARB is predicted to provide additive benefits in the prevention of cardiovascular diseases, through differential pleiotropic effects.

More than half of hypertensive patients are associated with insulin resistance and/or type 2 diabetes, and the coexistence of hypertension and diabetes markedly increases cardiovascular morbidity and mortality. ${ }^{12}$ Therefore, the development of an appropriate therapeutic strategy for hypertensive patients with diabetes is a key issue in achieving a successful reduction of cardiovascular diseases. Thiazolidinediones (TZDs), ${ }^{13}$ such as pioglitazone, are synthetic peroxisome proliferator-activated receptor- $\gamma$ agonists that act as an insulin sensitizer and are widely used as one of the major therapeutic drugs for type 2 diabetes. Interestingly, clinical evidence ${ }^{14}$ indicates that pioglitazone not only ameliorates hyperglycemia by improving insulin sensitivity but also reduces the incidence of cardiovascular events in high- 

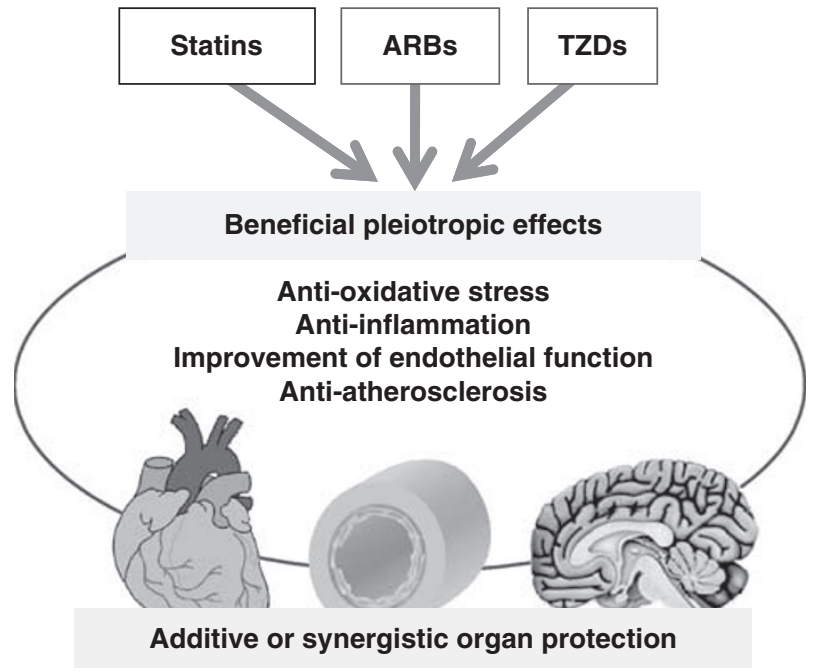

Figure 1 Beneficial pleiotropic effects of statins, angiotensin receptor blockers (ARBs) and thiazolidinediones (TZDs). These different classes of drugs, by different mechanisms, attenuate tissue oxidative stress and inflammation, leading to the amelioration of vascular endothelial dysfunction, atherosclerosis and cardiovascular remodeling.

risk type 2 diabetic patients, beyond blood glucose control. Importantly, emerging evidence shows that pioglitazone exerts multiple beneficial pleiotropic effects on not only adipose tissue but also cardiovascular and cerebral tissues. ${ }^{13,15}$ As the mechanisms underlying pleiotropic effects differ between pioglitazone and the RAS blocker, the combination of these different classes of agents is expected to exert an additive benefit in the reduction of cardiovascular morbidity and mortality. We have previously examined the potential benefit of a combination of an ARB (candesartan) and pioglitazone in hypertensive rats and have shown that their combination prevents cardiac hypertrophy, inflammation and fibrosis, and vascular endothelial impairment in hypertensive rats more than does either monotherapy, independent of blood pressure and blood glucose control. ${ }^{16}$ Furthermore, their combination exerts an additive suppression of cardiovascular NADPH oxidase activity in hypertensive rats, which is attributed to the additive downregulation of NADPH oxidase subunits, p22phox and Nox $1 .{ }^{16}$ Therefore, the additive benefits of the combination of these drugs, in terms of the prevention of cardiovascular injury, seem to be mediated by a greater attenuation of tissue oxidative stress than by either monotherapy. Our previous report highlights the combination of an ARB and a TZD as a promising strategy for the prevention or treatment of cardiovascular diseases in patients with both hypertension and type 2 diabetes.
From the preclinical studies described above, there is a strong scientific rationale for combining an ARB with a statin or a TZD in terms of treatment of cardiovascular diseases in high-risk comorbid patients (Figure 1). The combination of these different classes of drugs, besides normalization of blood pressure, lipid metabolism or blood glucose, exerts an additive or synergistic suppression of vascular endothelial dysfunction and atherosclerosis through a potent attenuation of oxidative stress and inflammation. Hence, a combination of an ARB with a statin or a TZD in one pill is expected to offer additive benefits with respect to the prevention and treatment of cardiovascular diseases in comorbid patients receiving long-term polymedication therapy. However, a large-scale clinical prospective trial is warranted to confirm this proposal.

\section{CONFLICT OF INTEREST}

The authors declare no conflict of interest.

\section{ACKNOWLEDGEMENTS}

This study was supported by Grants-in-Aid for Scientific Research from the Ministry of Education, Culture, Sports, Science, and Technology of Japan.

1 Nickenig G. Should angiotensin II receptor blockers and statins be combined? Circulation 2004; 110: 1013-1020.

$2 \mathrm{Kim} \mathrm{S}$, Iwao H. Molecular and cellular mechanisms of angiotensin II-mediated cardiovascular and renal diseases. Pharmacol Rev 2000; 52: 11-34.
3 Prasad A, Quyyumi AA. Renin-angiotensin system and angiotensin receptor blockers in the metabolic syndrome. Circulation 2004; 110: 1507-1512.

4 Yamamoto E, Dong YF, Kataoka K, Yamashita T, Tokutomi Y, Matsuba S, Ichijo $\mathrm{H}$, Ogawa $\mathrm{H}$, Kim-Mitsuyama S. Olmesartan prevents cardiovascular injury and hepatic steatosis in obesity and diabetes, accompanied by apoptosis signal regulating kinase-1 inhibition. Hypertension 2008; 52 : 573-580.

5 Abuissa H, Jones PG, Marso SP, O'Keefe Jr JH. Angiotensin-converting enzyme inhibitors or angiotensin receptor blockers for prevention of type 2 diabetes: a meta-analysis of randomized clinical trials. J Am Coll Cardiol 2005; 46: 821-826.

6 Shepherd J, Cobbe SM, Ford I, Isles CG, Lorimer AR, MacFarlane PW, McKillop JH, Packard CJ. Prevention of coronary heart disease with pravastatin in men with hypercholesterolemia. West of Scotland Coronary Prevention Study Group. N Engl J Med 1995; 333: 1301-1307.

7 Koh KK, Han SH, Quon MJ. Inflammatory markers and the metabolic syndrome: insights from therapeutic interventions. J Am Coll Cardiol 2005; 46: 1978-1985.

8 Kanno H, Iwai M, Inaba S, Senba I, Nakaoka H, Sone $\mathrm{H}$, Mogi M, Horiuchi M. Improvement of glucose intolerance by combination of pravastatin and olmesartan in type 2 diabetic KK-Ay mice. Hypertens Res 2009; 32 : 706-711.

9 Horiuchi M, Cui TX, Li Z, Li JM, Nakagami H, Iwai M. Fluvastatin enhances the inhibitory effects of a selective angiotensin II type 1 receptor blocker, valsartan, on vascular neointimal formation. Circulation 2003; 107: 106-112.

10 Yamamoto E, Yamashita T, Tanaka T, Kataoka K, Tokutomi Y, Lai ZF, Dong YF, Matsuba S, Ogawa H, Kim-Mitsuyama S. Pravastatin enhances beneficial effects of olmesartan on vascular injury of salt-sensitive hypertensive rats, via pleiotropic effects. Arterioscler Thromb Vasc Biol 2007; 27: 556-563.

11 Koh KK, Quon MJ, Han SH, Chung WJ, Ahn JY, Seo YH, Kang MH, Ahn TH, Choi IS, Shin EK. Additive beneficial effects of losartan combined with simvastatin in the treatment of hypercholesterolemic, hypertensive patients. Circulation 2004; 110: 3687-3692.

12 Verdecchia P, Reboldi G, Angeli F, Borgioni C, Gattobigio R, Filippucci L, Norgiolini S, Bracco C, Porcellati C. Adverse prognostic significance of new diabetes in treated hypertensive subjects. Hypertension 2004; 43: 963-969.

13 Duan SZ, Usher MG, Mortensen RM. Peroxisome proliferator-activated receptor-gamma-mediated effects in the vasculature. Circ Res 2008; 102: 283-294.

14 Dormandy JA, Charbonnel B, Eckland DJ, Erdmann E, Massi-Benedetti M, Moules IK, Skene AM, Tan MH, Lefebvre PJ, Murray GD, Standl E, Wilcox RG, Wilhelmsen L, Betteridge J, Birkeland K, Golay A, Heine RJ, Koranyi L, Laakso M, Mokan M, Norkus A, Pirags V, Podar T, Scheen A, Scherbaum W, Schernthaner G, Schmitz O, Skrha J, Smith U, Taton J. Secondary prevention of macrovascular events in patients with type 2 diabetes in the PROactive Study (PROspective pioglitAzone Clinical Trial In macroVascular Events): a randomised controlled trial. Lancet 2005; 366: 1279-1289.

15 Nakamura T, Yamamoto E, Kataoka K, Yamashita T, Tokutomi Y, Dong YF, Matsuba S, Ogawa H, KimMitsuyama S. Pioglitazone exerts protective effects against stroke in stroke-prone spontaneously hypertensive rats, independently of blood pressure. Stroke 2007; 38: 3016-3022.

16 Nakamura T, Yamamoto E, Kataoka K, Yamashita T, Tokutomi Y, Dong YF, Matsuba S, Ogawa H, KimMitsuyama S. Beneficial effects of pioglitazone on hypertensive cardiovascular injury are enhanced by combination with candesartan. Hypertension 2008; 51: 296-301. 